\title{
Esquinas
Fich
}

May 2013

\section{The Role of Universities in Urban Regeneration: Reframing the Analytical Approach}


This article was downloaded by: [Manuel Fernández-Esquinas]

On: 05 J une 2013, At: 13:53

Publisher: Routledge

Informa Ltd Registered in England and Wales Registered Number: 1072954 Registered

office: Mortimer House, 37-41 Mortimer Street, London W1T 3J H, UK

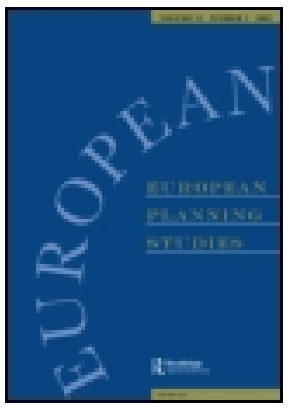

\title{
European Planning Studies
}

Publication details, including instructions for authors and subscription information:

http:// www.tandfonline.com/loi/ ceps20

\section{The Role of Universities in Urban Regeneration: Reframing the Analytical Approach}

\author{
Manuel Fernández-Esquinas ${ }^{a} \&$ Hugo Pinto ${ }^{b} \mathrm{c}$ \\ a Institute for Advanced Social Studies, CSIC-Spanish National \\ Research Council , Córdoba, Spain \\ ${ }^{b}$ Centre for Social Studies, University of Coimbra, Coimbra , \\ Portugal

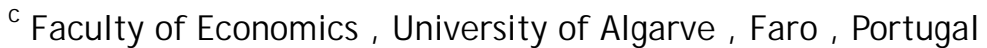 \\ Published online: 20 May 2013.
}

To cite this article: Manuel Fernández-Esquinas \& Hugo Pinto (2013): The Role of Universities in Urban Regeneration: Reframing the Analytical Approach, European Planning Studies, DOI: 10. 1080/ 09654313.2013.791967

To link to this article: http:// dx. doi.org/ 10.1080/ 09654313.2013.791967

\section{PLEASE SCROLL DOWN FOR ARTICLE}

Full terms and conditions of use: http://www.tandfonline.com/page/terms-andconditions

This article may be used for research, teaching, and private study purposes. Any substantial or systematic reproduction, redistribution, reselling, loan, sub-licensing, systematic supply, or distribution in any form to anyone is expressly forbidden.

The publisher does not give any warranty express or implied or make any representation that the contents will be complete or accurate or up to date. The accuracy of any instructions, formulae, and drug doses should be independently verified with primary sources. The publisher shall not be liable for any loss, actions, claims, proceedings, demand, or costs or damages whatsoever or howsoever caused arising directly or indirectly in connection with or arising out of the use of this material. 


\title{
The Role of Universities in Urban Regeneration: Reframing the Analytical Approach
}

\author{
MANUEL FERNÁNDEZ-ESQUINAS* \& HUGO PINTO**,† \\ *Institute for Advanced Social Studies, CSIC—Spanish National Research Council, Córdoba, Spain, \\ ${ }^{* *}$ Centre for Social Studies, University of Coimbra, Coimbra, Portugal, ${ }^{\dagger}$ Faculty of Economics, University of \\ Algarve, Faro, Portugal
}

(Received June 2012; accepted March 2013)

\begin{abstract}
Universities have resources for urban dynamics that are difficult to provide by other means. For this reason, these organizations are crucial actors in urban regeneration. This article sets out a conceptual framework for the analysis of the role played by higher education institutions in urban renewal initiatives. It is based on an integrated analysis of the uses of the university both as promoters of business innovation and in terms of their civic and social outcomes. Urban regeneration of cities in decline is used as a "strategic research site" to understand universities' potential. The discussion is organized around four types of contributions: physical infrastructure, human resources, economic development and civic engagement. The debate enlightens the options for integrating universities' capabilities as an asset for urban regeneration and sets out implications for the institutionalization of practices and decisionmaking in this field.
\end{abstract}

\section{Introduction}

Universities have specialized infrastructure and human resources that are difficult to provide by other means with the resources that local authorities often have at their disposal. For this reason, these organizations can be considered important assets in urban development strategies. The mobilization of their facilities, researchers and graduates can become an advantage in the transformation of urban environments. However, studies on the impacts of the university are weakly connected to urban development studies. On the one hand, research on the university's so-called "third mission" is sharply divided between a stream focused on social and civic uses and another addressing business

Correspondence Address: Manuel Fernández-Esquinas, Instituto de Estudios Sociales Avanzados, Consejo Superior de Investigaciones Científicas-CSIC Campo Santo de los Mártires, 7, 14004 Córdoba, Spain. Email: mfernandez@iesa.csic.es 
innovation. Furthermore, these effects tend to be studied at the national or regional level. Approaches using the urban scale can be considered relatively scarce. Meanwhile, studies on urban development, and more specifically literature on regeneration strategies, do not usually discuss the potential and impact of higher education institutions (HEIs) ${ }^{1}$ in all its complexity. Therefore, urban studies do not often consider analytical dimensions where universities play key roles in the creation of renewed urban dynamics.

The aim of this article is to put forward a comprehensive analytical approach on the role of universities in urban regeneration. The main proposal defended here is that to understand the potential of these organizations, it is necessary to consider their heterogeneous missions and at the same time, observe their implications for specific territorial sites. The article's strategy is, therefore, to achieve a cross-fertilization between the major fields of study dealing with the effects of universities at the local level. To this end, streams in the literature addressing different social and economic impacts of HEIs are brought together. The main components of the discussion are identified and relocated within an analytical framework tailored to cities that are seeking to integrate themselves in the knowledge society. The reflections for this article departed specifically from urban contexts that are being affected by processes of stagnation, declining or shrinkage that result in the deterioration of social and economic dynamics. Urban regeneration strategies for these cities seek to converge with those considered more economically and socially advanced. These environments can benefit enormously from the installed capacity of HEIs and thus are a "strategic research site" to understand universities' potential in urban renewal.

The article is structured as follows. After the introduction, Section 2 outlines the dynamics of knowledge transfer between universities and cities in the light of the changing roles of HEIs in contemporary society. Section 3 discusses the connection of the university with urban regeneration strategies. In Section 4, the article integrates these contributions presenting the main effects that universities have for regeneration strategies. These are included into an analytical framework containing four general dimensions: physical infrastructure, human resources, economic development and civic engagement. These dimensions are debated as a starting point from which policy-makers can unpack the main mechanisms for HEIs influence on urban regeneration. The university is considered in turn as an urban amenity, a promoter of population dynamics, a driver of economic development and an active actor for governance and social improvement. Finally, the concluding section discusses connections and tensions between different uses and the difficulties of building some of them at the local level.

\section{Universities, Knowledge Transfer and Cities}

The involvement of universities in urban affairs has a long history. The transformations experienced by both cities and universities over the course of the twentieth century have run in parallel, and in some respects, the changes in both have been strongly interrelated (O'Mara, 2012). HEIs have a strong presence in urban areas, in spatial and economic terms, as well as in political and social ones. In many cities, they are recognized as important catalysts of social transformations in environments marked by social deprivation or economic stagnation. Similarly, they often exert an important influence on local and regional policy agendas when urban revitalization strategies are being formulated. However, these issues have been addressed gradually from different perspectives 
of distinct fields of study, making it difficult to frame public practice in order to exploit universities' potential.

The main research streams have generally emerged from within epistemic communities with different professional backgrounds, sociologists and evolutionary economists on the one hand, and geographers and urban planners on the other, each focusing on specific issues. Although usually separated, both streams of the literature provide the theoretical building blocks from which it is possible to construct a framework for integrated analysis adapted to local contexts. In this section, we discuss the literature on knowledge transfer in relation to local environments, while in the next section, we address specifically the main approaches on urban regeneration.

In the field of innovation and higher education studies, both public policy and specialized literature are divided into two groups representing different visions of the "third mission"3 of universities (Molas et al., 2002): the economic role of the university as a force of development, mainly through business innovation, and the social role of the university related to community services and civic engagement.

\section{(a) The economic role of universities}

Regarding the first group, universities have often been described as "the driving force behind growth" as they generate educational capacities, skills and research results that are relevant to innovation, particularly in certain industrial sectors (Mansfield, 1991). The understanding of the specific channels and mechanisms by which this contribution occurs is far from homogeneous. Over the last two decades, there are two important trends in the studies on the economic impact of HEIs: first, a shift from a focus on scientific production and high-tech spill-overs to a focus on a diversity of channels and mechanisms of knowledge transfer where modes of tacit knowledge become relevant. Second, a shift in the territorial scale, consisting in a change of focus from the national level to the regional level, and more recently to the local level.

Both processes imply a changing role in universities' mission where new actors and institutional dimensions mediate the process of knowledge transfer. The complexity of the role of the university is well summarized in the proposal by Uyarra (2010). Here several models of university roles implying different spatial aspects of interactions are identified, as well as different mechanisms for university engagement. First, universities were considered as "factories of knowledge" whose impact was primarily driven by knowledge spill-overs. Second, studies on university-industry links assumed a "relational" or collaborative role, where universities were seen as privileged partners for larger companies appropriating technology strategic to their activity. Later, it was acknowledged a variety of bi-directional links and processes of knowledge sharing with a diversity of firms (Gunasekara, 2006). More recently, the "entrepreneurial" model of universities have been encouraged though organizational arrangements and intermediary actors such as technology transfer offices, science parks and liaison structures (Clark, 1988; Guston, 1999; Etzkowitz et al., 2000). Finally, innovation studies tend to see universities as "boundary-spanning institutional nodes" whose influences are shaped by the specific regional innovation systems in which they are embedded. The university began to be seen as an actor capable of diluting distances between the various nodes of innovation systems where it belongs (Cook, 2005). 
Despite the economic potential of HEIs, there are multiple and contradictory mesages about the benefits that universities are able to provide. These discussions and contradictions are being translated into the local dimension of the process of knowledge transfer that is emerging recently. Strategic concepts and intercity competitions referring to "knowledge-based urban development", "creative cities" and "science cities" indicate that urban planners and politicians are beginning to search for strategies to take advantage and to make use of this potential (Franz, 2011). In the light of this policy trend, a relevant group of studies addresses the so-called knowledge cities (Carrillo, 2006) or knowledge spaces (Moulaert \& Sekia, 2003). Some of them highlight the diversities of approaches by which university assets can benefits the city. For instance, Benneworth et al. (2010) document the relationships between universities and local authorities. Departing from case studies of five cities, they find models between the extremes consisting of the socalled "stand alone" campus and the "high tech" campus. Although they select successful stories and cities that are core locations, they show several ways of engagement that mobilize some key assets, such as specialized localizations and contributions to urban management. In other studies, the impact focuses on spin-off firms adapted to local skills (Benneworth \& Charles, 2005). The relevant issues in this approach include technology transfer, the promotion of entrepreneurship and the clustering of firms with innovation capacities in the local context (Guerreiro \& Pinto, 2012).

These studies have usually been applied to poles of high-tech innovation that are considered to be examples of good practice. They are often located in regions characterized by their leading capacity in the knowledge economy, rather than in cities involved in processes of development seeking to converge with global trends, and much less in cities in decline. Interestingly, the criticism about the diversity of local contexts is similar to the one occurred in studies at the regional level. It would be misleading to generalize from these cases since universities play different roles in different territorial sites and scales (Uyarra, 2010). Other authors are focusing their interests on non-core contexts that go beyond technology transfer strategies centred exclusively in science parks and incubators (Pinto et al., 2011). Some of them encompass the mix of strategies adapted to old industrial contexts, although at the city level, there are not many systematic studies applied to the "ordinary" or less successful cities.

An important part of the discussion is that certain linkages and process of knowledge transfer can be more local than others. For instance, university-industry links at city level may have a different technological component depending on the absorptive capacities on local firms. Moreover, the economic goals of governmental departments and local organizations may be more interrelated to social and environmental aspects that are relevant to citizens' employment needs and the quality of life. Nevertheless, many of these studies developed at the city level are difficult to connect to other dimensions. The goals of economic and social cohesion tend to have less visibility and are implicitly considered only as indirect effects that are usually not present in approaches focusing on innovation systems.

\section{(b) The civic and social role of universities}

The second group of studies related to "third mission" concerns universities' direct involvement in social problems in their immediate surroundings, with a special focus on improving social living conditions and activities that empower communities for collective 
action (Diamond, 1999). The priority themes in this current of research are combating social exclusion, promoting health and education among disadvantaged groups. This social role dates back to the nineteenth century and is rooted in the founding mission of many HEIs, although with different denominations and sensibilities. A useful example for documenting recent thinking is the proposal of the civic university (Goddard, 2009). It is argued that HEIs have the civic duty to engage with the whole of society, locally, nationally and globally, linking social and economic development, and promoting place-based leadership. The civic university is concerned with the dilution of borders, particularly between public and private spheres, recruiting individuals capable of translating interests and building bridges between different types of agents. But this dilution is not only focused on transactional interventions associated to clear outputs, such as patents, spin-offs firms and contract research, but transformational mechanisms that are more difficult to quantify. The civic university attempts to scrutinize its action, concerned with the results of interaction with society.

There is increasingly greater recognition that universities can and should do more to help solve social problems in areas where they are located. This could positively contribute to the research agendas practiced by HEIs, the learning experiences of students, in addition to direct benefits to local stakeholders. For some authors and university managers, the notion of public commitment of the university is not a simple addition in the existing functions of universities. Rather, it should redefine the nature of the university itself (Watson, 2007; Goddard, 2009).

The multiple social roles encompassed by the above vision are not documented in regular academic studies as much as the other roles. Despite the fact that universities' tradition for social involvement goes back much further than their linkages with firms, and remains present in many prestigious universities, these services are not usually integrated with the universities' formal teaching or research structure. Studies on the social mission are poorly connected with the economic orientation of universities, and are largely absent in the literature on knowledge-based development. However, there is an explicit trend since the late 1990s in linking universities with local communities. Prestigious universities with important economic endowments, such us Penn and Harvard, are strengthening their agreements with city governments and making their programmes more visible. International organizations and collectives of universities are also playing an important part in setting the agenda (for instance, Compact Campus in the USA). OECD (2007) conducted international reviews on the roles of HEIs in regional development, clearly underlining that the roles of HEIs are not only economic but social, cultural, environmental and are usually grounded in local sites. ${ }^{4}$ As a result, there is a growing information on community and social engagement, mainly through case studies, reports and a number of specialized programmes related to community services.

\section{(c) Caveats for knowledge transfer at local level}

The above broad dimensions of knowledge transfer are rather disconnected. Approaches aiming to understand the impact of universities holistically were not significant in social research or in specialized scientific publications on universities' missions, particularly when compared with the abundance of literature and policy documents on regional innovation. Some authors argue that "the literature fails to clearly spell out the integration 
of various university missions organizationally, and within different types of universities" (Uyarra, 2010).

A general problem is related to disentangling the scales of possible impacts of universities. When descending to the local level, other implications need to be taken into account because of the specific dynamics of cities when compared to national and regional levels. In urban contexts, some uses of the universities acquire a more important meaning. First, some dimensions of knowledge transfer are more evident, such us social services, health and community empowerment. At the local level is where the civic role of the university is perhaps more demanding. Regarding the firm side, the benefits are not only related to the knowledge reservoir and the capacity to produce research useful for some companies, but also to the potential for fulfilling the needs of local firms. The presence of the university may be a connection with global knowledge that may be useful for resolving their productive problems. Second, the space concentration implies a different set of relationships with municipal governments and local actors (citizen collectives, associations, etc.) that may have distinct expectations. These interactions are also more direct and required a process of adaptation to collectives that are different from the stakeholders that usually interact with universities, such as governmental branches, regional innovation agencies and certain groups of firms.

From a policy point of view, an important problem has to do with institutionalization of links. It is well known that universities and research centres occupy distinctive institutional fields that are often far removed from local areas of action (Drori et al., 2003; Westnes et al., 2009). The development of universities in the modern world used to be linked to the education of the ruling classes and civil servants. Later, during the expansion that took place in the twentieth century, in most of the developed world universities became corporate entities supported by public funds whose mission was to provide public goods, mainly in the form of professional training and published scientific knowledge. This is usually reflected in the two major missions of teaching and research towards which universities are oriented. Universities are, therefore, organizations with goals that sometimes have little to do with local needs. On the one hand, they have specific internal systems of governance with a high degree of autonomy. Their targets are set by academic bodies responsible for their regulation and funding, which are usually remote from decision-making levels in urban areas. Scientific communities rooted in academic culture have as their reference groups the so-called "invisible colleges", (Crane, 1972) which act as peers to certify those outputs that are considered valid contributions to knowledge and at the same time to grant the rewards that serve as the currency for the evaluation of the achievements of academic workers and institutions. What is more, excellence in academic and scientific terms often results in a distancing from the territory. Usually, the more significant and successful the scientific and academic output, the more globally oriented the university becomes, and the more detached from the local context. When the university reaches a high degree of research competence and internationalization, the governance of scientific life tends to take the scientific communities and organizations governing international science as their reference framework and the basis for their efforts to attract resources. At the same time, demands from the local bodies are often unrelated to the demands of scientific and university life. Sometimes they are related to research problems that are difficult to translate into cutting edge research from which published results may be obtained. At other times, the dynamics of local work are often incompatible with the dedication to study and the orientation to obtain measurable scientific output, which 
normally requires a high degree of specialization. For these reasons, university involvement is often barely visible in the processes of local development. That is why some activities, especially the provision of advanced services and the social engagement, are usually seen as separate agendas from the functions of research and technology transfer from codified knowledge. The connection between the two orientations usually needs special institutional arrangement directed at facilitating a common goal and mutual benefits.

Therefore, when discussing the possibilities for capturing the benefits for the local level, specific assumptions are needed focusing more specifically in knowledge transfer dynamics adapted to local nodes. Two important questions are: how can the different functions be integrated into the city context? How can these functions be combined with the global orientation of the universities as providers of knowledge? A necessary step is to look at the other side of the relationship and explore the possibilities of connecting urban dynamics to some of the functions developed by universities. The field of urban regeneration is perhaps more useful for connecting both streams.

\section{Universities and Urban Regeneration}

In comparison with higher education and innovation studies, the field of urban regeneration is formed by a distinctive epistemic community, mainly comprising geographers and urban planners, in which a diversity of approaches to urban development also coexists. The subjects of urban regeneration have traditionally been the provision of physical infrastructure and the revitalization of the housing stock in declining urban areas. Urban regeneration is often understood as a process of slum clearance and physical renewal of a particular city area (Roberts \& Sykes, 2000).

More recently, studies of this kind have broadened their field of attention (Kearns \& Paddison; 2000, Couch et al., 2003). In some cases, the shift is the result of regeneration initiatives that were controversial when policies promoted specific production and consumption practices connected with services or some industrial sectors loosely connected to knowledge economy (McCarthy \& Pollock, 1997). In other cases, the evolution of urban regeneration strategies was connected to governance problems, especially the difficulties for involving local networks in decision-making processes at the regional or national levels that were crucial for cities.

The traditional vision of urban regeneration is being enlarged to a notion that recalls a concerted action towards social, economic and physical improvement in urban areas that experience multiple deprivations in order to create sustainable communities and quality of life (Couch et al., 2011). This vision has been discussed in the last years by the EU (Couch et al., 2003) to strengthen the urban dimension of cohesion policy. They seek to create the conditions for an integrated urban regeneration that facilitates smart, sustainable and social inclusive growth (EU Ministers for Urban Development, 2010). It is relevant to stress that actions for urban regeneration differ considerably from country to country, even when comparing EU member-states, especially because of different planning cultures (Knieling \& Othengrafen, 2009). Models of urban regeneration also differ because of the economic models of capitalism, the context of economic growth, path dependencies related to the development and implementation of policy tools and governance, and the political cycles (Couch et al., 2011), although it is possible to identify common components.

For the purpose of this article, a useful notion of urban regeneration draws in the contributions of Roberts and Sykes (2000), as a comprehensive and integrated action that 
enable urban problems to be solved, and actively seeks to provide a lasting improvement in the physical, economic, social and environmental area that is subject to the process of change. Specifically, this approach calls for the combination of several key dimensions. They are related to physical infrastructures, such as facilities and housing, population and human resources dynamics, different aspects of economic redevelopment, both the innovation of existing firms and the creation of new sectors, and the social and civic components for which the governance acquires a more comprehensive meaning.

In line with this, new realignments of urban policies can be observed in relation to the role of universities. In addition to physical planning and land use, there are also more holistic approaches that take educational, cultural and social aspects into account as essential resources for development processes, and envisage that these factors can sometimes be contributed by HEIs (Paddison et al., 2007). Other relevant approaches integrate the university as a key player in local innovation systems (Rantisi, 2002) or to the emergence of "creative" environments (Landry, 2000; Florida, 2003). In addition to providing resources for business innovation, these approaches observe how universities foster the creation of human capital and help connect the local context with technological developments with a global impact. However, although these studies have the advantage of considering knowledge-based urban development processes, they rarely take into account the multiple functions that universities can play in cities. As a result, the role of the university at the urban level, acting simultaneously as an engine of economic development, an inducer of qualified human resources, a political actor and as a promoter of social welfare, has been somewhat under-explored.

\section{Towards a Map of University Uses in Urban Regeneration}

The approach taken here starts with four components commonly identified in the processes of urban regeneration. The first dimension encompasses physical infrastructure. The second refers to the dynamics of population and human capital. The third covers economic development referring specifically to the sources of wealth deriving from firms' productive activities. Finally, the fourth dimension regards the intervention in social issues and the role of governance. ${ }^{5}$ Additionally, each one of the above dimensions has been divided into two parts, separating out the effects of measures that tend to form an explicit part of regeneration strategies from the indirect effects (see Table 1). This division facilitates the understanding of both not specifically planned effects, in particular spill-overs, and the more proactive uses of universities in strategic planning processes.

It is not easy to clearly differentiate these effects from each other in practical situations. Given that the university can be considered a major piece of urban infrastructure, its implications are obvious simply because it is a visible organization and it occupies an important social and economic space within the dynamics of the city. In other words, universities have an effect by the mere fact of their presence. Consequently, it is possible to consider all the dimensions as indirect effects in urban regeneration strategies (Franz, 2010). However, the following proposal differentiates the second set of consequences concerning the uses of universities designed to perform a mission related to some of the city's economic or social needs. Compared with the former, this group usually represents an additional step in the role of the university when it is included with a specific function in an urban regeneration strategy and its possible effects are reflected in strategic planning processes. Therefore, this perspective envisages the university as a proactive actor and entails its direct participation in various types of social and economic issues. 
Table 1. The role of universities in urban regeneration: dimensions and effects.

\begin{tabular}{|c|c|c|}
\hline Dimensions & Explicit effects & Implicit effects \\
\hline $\begin{array}{l}\text { Physical } \\
\text { infrastructure }\end{array}$ & $\begin{array}{l}\text { The university as an agent of urban } \\
\text { planning } \\
\text { - Property development } \\
\text { - Reclassification of land for building and } \\
\text { urban uses } \\
\text { - Provision of infrastructure and } \\
\text { "knowledge spaces" (services for } \\
\text { science and technology parks, ICT } \\
\text { - Gecess, etc.) }\end{array}$ & $\begin{array}{l}\text { The university as an amenity and } \\
\text { attraction in urban life } \\
\text { - Access infrastructures } \\
\text { - Provision of cultural and sport } \\
\text { facilities } \\
\text { - Provision of green space }\end{array}$ \\
\hline $\begin{array}{l}\text { Human } \\
\text { resources }\end{array}$ & $\begin{array}{l}\text { Training and specialization } \\
\text { - Production of graduates for strategic } \\
\text { - sectors } \\
\text { - Specialized training for workers } \\
\text { - Influx of university-educated population } \\
\text { - Circulation of knowledge workers }\end{array}$ & $\begin{array}{l}\text { Population dynamics } \\
\text { - Demographic change } \\
\text { - Social mobility } \\
\text { - Spatial mobility } \\
\text { - Increase in educated workforce }\end{array}$ \\
\hline $\begin{array}{l}\text { Economic } \\
\text { development }\end{array}$ & $\begin{array}{l}\text { The university as an agent of innovation } \\
\text { - Knowledge transfer to businesses } \\
\text { - Businesses incubation } \\
\text { - Provision of knowledge intensive } \\
\text { services } \\
\text { - Creation of knowledge clusters: } \\
\text { attracting R\&D businesses, coalitions of } \\
\text { territorial development }\end{array}$ & $\begin{array}{l}\text { Economic revitalization } \\
\text { - Generation of sources of income } \\
\text { (university as local employer) } \\
\text { - Revitalization of local suppliers } \\
\text { (university as customer of local } \\
\text { businesses) } \\
\text { - Creation of new businesses to } \\
\text { meet the university's demand } \\
\text { - Attracting businesses relating to } \\
\text { university specialization }\end{array}$ \\
\hline $\begin{array}{l}\text { Civic } \\
\text { engagement }\end{array}$ & $\begin{array}{l}\text { University's social commitment } \\
\text { - Applied research and consulting focused } \\
\text { on local policies } \\
\text { - Involvement in solving social problems: } \\
\text { special education, poverty, nutrition, } \\
\text { health education } \\
\text { - Strengthening community capacities }\end{array}$ & $\begin{array}{l}\text { Social and cultural capital } \\
\text { - Enhancement of population's } \\
\text { capacity for involvement in local } \\
\text { issues } \\
\text { - Increased public participation } \\
\text { - Higher density of social } \\
\text { networks }\end{array}$ \\
\hline
\end{tabular}

Source: Own elaboration.

Table 1 also identifies in the cells the components that are able to function as development mechanisms along the four dimensions. The analysis begins with the basic effects, and then unfolds each of the components and relates it to others that are associated with the social and economic structure. Regarding the empirical evidence, it is difficult to capture and measure the full spectrum of universities' social and economic consequences 
empirically. The socio-economic impacts are often better understood when qualitative aspects are considered. As a support for the analytical framework, some examples are offered to help illustrate the specific influences and relationships between the dimensions. In particular, this article considers that some cities that locate a university can be a strategic research locus enabling the mechanisms by which HEIs can be used as tools of change in urban environments. It is assumed that certain kinds of urban contexts, especially shrinking cities, are a more suitable environment for explaining the role that universities may play in urban regeneration. ${ }^{6}$ Some of the examples for illustrating the mechanisms focus on these cities.

\subsection{Physical Infrastructure}

Universities have traditionally been considered a social amenity and attraction for population because they encompass a type of infrastructure that is often unique and difficult to obtain from other organizations. The gardens, roads and access ways, adequate energy supplies, together with the communications technologies required to set-up and run a campus, all have, in themselves, a positive effect on those urban areas in which campus environments are sited. The location of universities is, therefore, considered an implicit asset for development, especially in impoverished or backward settings.

In addition to this effect, the construction of new buildings and accesses, or the conversion and reuse of old buildings, such as industrial buildings or military barracks, into university infrastructures have an obvious effect in terms of renewal and gentrification that enhances the value of the surrounding real estate (examples of gentrification are, among others, @22 in Barcelona, the endowments of Brighton and Sussex University and the integrated plans of Leuven University).

The infrastructure designed for students and researchers can provide a service to communities, especially hospitals, sports facilities, libraries and telecommunications, which are particularly difficult to build and maintain when they are intended for use by small neighbourhoods. For this reason, universities can be a cost-effective way for local authorities to provide services to the community if their facilities can be made available to the general public. What is more, when some cities achieve high levels of social and economic development, these cultural and sporting facilities can serve as factors attracting new groups of people to move into the area. Combined with an educated population, having an economic fabric endowed with innovative firms and an attractive offer of leisure and cultural activities, universities are essential factors of approaching the so-called "creative cities" model (Landry, 2000; Florida, 2003).

A more direct intervention in addition to the provision of infrastructure is the creation of "knowledge spaces". In some countries, universities are major landowners, or have benefited from public grants, or private donations of property. There is already a long history of universities' active involvement in land use as a means of attracting businesses and creating new production facilities. Perhaps the most significant example is that of the US public universities, where the so-called land-grant universities were founded by transfers of federal lands to the states in the second half of the nineteenth century (Etzkowitz \& Klofsten, 2005). More recently, science parks are the best-known exponent of providing land and physical infrastructure for new businesses. In some cases, they have given rise to strategic partnerships with other organizations. The usual partnership with local authorities consists of municipalities allowing the reclassification of land and providing access 
ways, with the universities providing land and attracting human resources, and with governments, together with some companies, providing financial resources and institutional arrangements that facilitate conversion of spaces and the creation of poles of activity (Lindelöf \& Löfsten, 2003).

Another lesser-known activity in this area of study is the role of universities as agents of urban planning, where their facilities are designed specifically to play a role in the development of the city, at times acting as urban developers. Although this role has been studied only in few places, there are numerous examples of university initiatives aimed at creating differentiated urban dynamics, and of governments using policies of university location to improve the quality of life through the use of public resources (O'Mara, 2007). The university itself has sometimes been the starting point for territorial development. Again, the classic examples are the US land grants, which led to towns growing up around campuses. There are also significant examples of this in Asia and Europe (Perry, 2005). Also, more recently, universities have acted as a kind of seed for other uses, especially in the case of policies for fostering creative cities (Mustard \& Murie, 2010), which aim to locate innovative economic and administrative sectors near a well-educated population. At other times, the responsible government body for the university uses the expansion of the campus as a tool to implement urban renewal projects, especially when located in critical locations that help change the social and demographic dynamics of declining areas. It is worth distinguishing these initiatives from the classic science parks, which aim to offer a location for high-tech companies. An interesting example is that of new spaces in old city centres, or the run-down areas of large cities, which attempt to integrate cultural industries and knowledge-intensive services that can offer alternative employment to the local people. In other cases, new campuses have also been used to expand cities, creating corridors between scattered communities with the intention of producing more compact urban areas, or to lessen the isolation of suburban areas.

From a urban regeneration perspective, the common response is to arrange coalition of interests between universities and city governments, often using hybrid consortia for land development in order to accommodate urban planning and university needs, although a highly contested issue is to combine interests of different stakeholders related to the land use. The challenge is still being the discussion over suburbs vs. the city centre. After decades of suburbanization, the issue is to accommodate again university life into common city dynamics, although these trends are difficult to synchronize because of the long time-frame needed for developing infrastructures (see, for instance, the special issue on universities and spatial development in the International Journal of Knowledge Based Development; Franz, 2011).

\subsection{Human Resources}

The presence of a university often has an implicit impact on the population dynamics of the city in which it is located, especially in the case of medium-size cities due to the university's greater relative weight in comparison with large cities, although it is also possible to observe this effect in metropolitan areas whose population is stagnant. The demographic composition of a large university includes a disproportionate number of younger people with a relatively high level of educational attainment. The university population also tends to be diverse in its cultural and geographic origins. Additionally, this population 
is characterized by having a greater propensity for both spatial mobility and social mobility between classes.

As education and training are the university's primary missions, their effects are usually evident in terms of the creation of groups with greater cultural wealth and education, resulting in more flexible and diversified labour markets. The social and economic impact of educating students is widely recognized as a fundamental factor in the development of countries and regions. However, it is difficult to study in specific local environments. Some authors have even found limited evidence about the effects of local universities in promoting regional innovation (Faggian \& McCann, 2009). Nevertheless, it is generally considered that the benefits of education and social mobility are important insofar as higher education helps enable higher rates of entrepreneurship and to create higher value-added jobs with better working conditions, which in turn can provide a stronger tax base for the local coffers.

However, there may be a more explicit effect when the production of degrees conforms to a specific strategy tailored to the needs of the surrounding economic area. In this case, universities can be major players in human resources policy planning when they channel students and professionals into economic sectors that need to raise their competitiveness, or towards new companies with the potential to replace old productive sectors or create new business nuclei. Other planned effects include the production and circulation of knowledge workers. Some universities create segmented labour markets that establish interactions with their areas of influence, generating flows of human resources which may have an economic impact. Sometimes they can produce a high degree of concentration of specialists in strategic sectors, or channel teaching staff and academic researchers towards companies related to their areas of research, where they can provide consultancy or perform applied research. Universities are an important anchor for the attraction of the "creative class" (Florida, 2003). At other times, they can generate transitions in both directions between academic science sector and other public and private sectors. Consequently, higher education organizations can be used as a tool for urban regeneration in ways usually associated with strategies pursuing transitions to the knowledge economy, as for instance in the city of Coimbra (Casaleiro, 2011). In any case, what usually happens is that graduate migration has an important effect on innovation and other social dynamics, the destiny of graduates being the key issue. An important challenge for city governments in peripheral cities that lack a vibrant economy is both to attract graduates and to keep an important part of the local graduates in the local economy. That is why strategies based on human resources needs to be combined with other components that help to attract and retain skilled personnel.

\subsection{Economic Development}

The economic role played by universities can also be subdivided by considering the implicit effects separately from those arising as a result of a planned strategy. It is evident that universities may bring considerable human and financial resources to cities, along with other providers of public goods such as hospitals and state school networks. Such organizations are often the largest employers in medium-sized cities whose productive structure is mainly made up of small- and medium-sized enterprises, which is important for local economic dynamics on various levels. For example, universities create a substrate of middle-class consumers, consisting of both their employees and stu- 
dents, who may play a role in revitalizing the local economy. HEIs can also be used as a stimulus for local businesses when they draw upon them as providers of the goods and services teaching establishments require, sometimes bringing small businesses onto the campus. Moreover, examples exist showing how the indirect employment stimulated by the activity of large universities can have an effect on the dynamics of regional development (Saxenian, 1996).

The economic impact of innovation is possibly the single most recognized aspect in the specialized literature and in public practice when it comes to the role of universities as active agents in development policies. In this matter, it is convenient to unfold the possible impacts of universities on industry development at the city level. Universities may be considered drivers of innovation through various channels and by a variety of mechanisms. First of all, when researchers and research facilities are accessible to local businesses, they can be used as providers of knowledge-intensive services. Although the emphasis of most studies of innovation has been on the role of patents and codified knowledge, is widely recognized that informal channels of knowledge transfer offer a wide variety of possibilities ranging from consultancy and applied projects, to the use of scientific instrumentation, and the provision of testing and laboratory services (Ramos-Vielba \& Fernández-Esquinas, 2009).

Second, the specialized training for enterprises and the internships they provide undergraduates and doctoral students are also effective mechanisms through which to increase staff recruitment and, potentially, firms' absorptive capacity (Fernández-Esquinas et al., 2010). Third, the university can act as an agent for the promotion of entrepreneurial activities, or as an entrepreneurial body itself. The main channels in this regard are entrepreneurial education, guidance of students on business creation and the setting up of incubators to help establish new high-tech firms. University start-ups may have also relevant impact in less-developed regions when compared with the typical high-tech examples that are highlighted in core locations (Benneworth \& Charles, 2005). Fourth, another common channel relates to clustering dynamics. Although this can sometimes be considered an indirect effect, special importance is often given to the location of universities and industrial areas in S\&T policy decisions. The location of high-level scientific centres, especially in the case of large infrastructures, can have significant impacts on the surrounding areas due to the spill-overs between research and business innovation and the capacity to attract companies in knowledge-intensive sectors. S\&T parks are probably the most visible example of how agglomerations and economic revenues can be generated by universities.

This broad set of mechanisms for knowledge transfer and co-production of knowledge gives special importance to geographical proximity and the ease and closeness of social relationships. It is widely recognized that the circulation of knowledge is linked to the existence of dense networks of interactions between universities, interface organizations, groups of academics, knowledge-intensive companies and providers of specialized services (Fritsch \& Monz, 2010). The existence of these dynamics requires prior processes of development that are sustained over long periods of time so as to lead to stable organizations equipped with the necessary capacities. That is why the cases considered to be most successful are geographically concentrated in research nodes. However, it is worth considering other experiences which, despite not being known as outstanding places of excellence in the knowledge economy, have used universities' capabilities as a tool for urban regeneration strategies. In cities located in peripheral environments in terms of 
science and technology, it might be worth considering the development of strategies based on knowledge in a diversified way in order to encompass the renewal of traditional potential. Business innovation, either through capabilities in existing businesses or through new start-ups, can be promoted through partnerships between public and private entities and local governments, including traditional business associations, or between groups of citizens (for instance, the so-called "coalitions of regional development", Asheim \& Coenen, 2005), all aimed at making local capacities economically viable. In this regard, obtaining value from architectural and historical legacies, traditions and crafts, renewing declining industries and promoting service industries based on the use of tacit knowledge, such as in the case of tourism and cultural services, are niches whose potential for job creation in shrinking cities may even exceed that of initiatives based on scientific research.

A common response is, therefore, to try to connect local resources and capacities developed with previous industrial base with more viable sectors in the global economy, although the main challenge is to find new modes different from that of the previous development processes based on agglomeration. The traditional model of local development has been associated with the concentration of firms specialized in a production sector, usually manufacturing. Intense interactions between firms, formal and informal training, circulation of workers and specialized providers of services and products, all function as strategic inputs that strengthen the productive capacities. These niches used to form the "local buzz and global pipelines" (Bathelt et al., 2004) where the intense interactions constitutes the competitive advantage to make the local product competitive in the global market, although the role of HEIs was not always present, and mostly was implicit and concentrated on the training of human resources. Nevertheless, this model is being superseded in traditional industrial districts, especially in Europe, as a result of the emergence of multiple local sites around the world that show similar competitive advantages. Global competition is producing symptoms of crisis in traditional core districts and local milieus that are forced to compete by lowering wages and offshoring part of the production. A way to maintain competitiveness of local industries is to catch up with new models of production consisting of more global distributions and circulation of knowledge. Not necessarily in terms of codified scientific knowledge, but trough specialized networks of producers, workers and providers of specialized services that may be located in many different places. In this model, production is still localized and agglomerated, although the rationale of agglomeration is different since these are nodes of local production connected to the global networks of knowledge. It may be called a combination of "global knowledge networks" and "local production nodes" (Asheim et al., 2007). In this new challenging mode, the actors adopt a different role since it is necessary to combine analytic knowledge accumulated by universities with synthetic and symbolic knowledge available locally. That is why universities are being seen as a more important strategic partner: because of their capacities to engage in global network of distributed knowledge.

There are useful examples of these dynamics in old industrial cities in the process of shrinkage. Norrköping (Sweden) is a case of declining labour-intensive industries considered successful in creating a road to urban regeneration through the connection of the city with the university strategy. In particular, they used research and human resource potential for superseding local economies by developing alternative industrial sectors aligned with the current economic base and at the same time more connected to global technological advantages. In other cases, the strategies have relied more in the creation of creative industries, dedicated to cultural sectors in the broad sense (Flew, 2012) and 
firms engaged in Knowledge Intensive Business Services (Simmie \& Strambach, 2006). In some places, such as in some East German cities, and particularly in Berlin neighbourhoods (Franz, 2008) these companies are considered to be the most important source of employment and economic activity, and also to constitute the substrate allowing for the growth of science and technology intensive firms.

\subsection{Civic Engagement}

Regarding the civic role, universities are a resource which implicitly may help to raise the level of skills in relation to both civic matters and the community's level of social integration. The possibilities for involvement in local issues of a social and political nature are greater when there is a larger educated population. A population with a higher educational level has better cognitive skills with which to perceive the mechanisms underlying social problems. They are more committed to the governance of the city and at the same time, are endowed with the resources that facilitate the acquisition of social capital. These are all conditions for enhancing citizen participation (Rowe \& Frewer, 2000). At the same time, relations between politicians, local technical staff and academics and improve public sector performance. Sometimes university staff and student leaders are also part of citizens' movements involved in decision-making processes and thus are able to influence local political agendas. Moreover, when the population has a higher level of educational attainment, policy-makers are often more sensitive to discussing issues that might otherwise have difficulty achieving visibility and public attention. This is particularly so in the case of complex issues requiring the active participation of groups with appropriate cultural skills.

University leaders and social activists have always been aware of the potential of higher education establishments in processes of social mobilization. Indeed, there is a long tradition of university participation in social and political issues, longer even than in technology transfer activities or the commercial exploitation of research. Civic engagement can be viewed as one of the founding missions of some of today's most influential universities. Initially, the ideal of civic education, promoted by philosophers of education such as John Dewey, was one of the main driving forces for this mission (Harkavy, 2000). However, more recently, there has been a growing and much more intentional trend within the universities' organizational structure towards civic engagement. This can also be divided into two major streams.

The first is the growing role of applied research, particularly since the 1980s. Although the emergence of research-oriented public intervention also dates back several decades, with some particularly vibrant moments, especially in the 1920s and 1930s following the university reform movement in the English-speaking world, and later in the 1960s when universities took on an active role in promoting equal opportunities policies, the need to gain legitimacy and funding sources in times of economic adjustment, such as in recent decades, have produced universities that are more open. Local authorities have begun to be significant "clients" for universities. The municipalities can draw upon academics in the immediate environment as consultants with whom it is easier to interact, and they can run applied projects tailored to local needs. The second trend is the relationship between the university and local community bodies, often termed "community service" or "community engagement". This mission is organized around services for learning, welfare centres and institutes to empower the local population, especially present in higher education systems of North America and Australia. Significant efforts have been 
made in areas such as special education, nutrition, health, social integration of groups at risk of exclusion and community empowerment (Wergin, 2006).

The social and civic role of universities in European countries does not have a particularly high profile. Although significant instances of social engagement can be identified (ESF, 2007), historically in most of Europe the development of social services has been driven directly by government on various levels. Economic support for social issues is usually the responsibility of national and regional levels, and the provision of personal care falls largely on municipal social services. Therefore, the most significant examples are to be found in the USA and Latin America, due to the different political and institutional setting of social protection and the specific role played by non-governmental bodies vis-à-vis the role of the state.

In the USA, university social engagement is part of a movement that began in the 1930s, expanded in the late 1960s and has evolved over the last two decades towards a greater degree of institutionalization and specialization. The creation of special centres, councils and advisory groups, tailored occupational profiles and career structures, and a specific budget for these missions, are all mechanisms explicitly designed to have a social impact on the local communities. Sometimes these centres and programmes have helped establish a dense network of relationships with the social services belonging to other administrative bodies. At other times, universities are recipients of funding from private philanthropic organizations, leading to the creation of specific programmes that have a particularly active role in maintaining and spreading this social mission. There are already some associations of universities whose goal is to put this practice on an institutional footing, such as Campus Compact in the USA (Boyte \& Hollander, 1999). The Latin American case represents another example of experience with the university's civic mission, though for different reasons (Rodríguez-Gómez, 1999). In some countries, universities are among the organizations best equipped to undertake this mission, and many universities were created by philanthropic bodies. They, therefore, play an important role in complementing and sometimes making up for the lack of a network of public social services able to reach the entire population.

An important challenge is the connection of the social role with the other uses of universities. In particular, this vision of a "civic university" is relevant to the global understanding of localized innovation systems. At the local level, the university may strengthen innovation in enterprises and qualification of human resources adapted to existing or latent needs. It may contribute to the expansion of cultural and creative activities, and integration into a more inclusive society. It may favour the setting of agendas on society's problems, and enable the effective interconnection between national actors and the localized system of innovation. Although locally encrusted, it is argued that the civic university may be globally competitive, encouraging investment and external financing, the attraction and retention of talent, and connection possibilities of local actors with transnational networks. Therefore, an important issue in policies pursuing the civic university is the promotion of place-based leadership (Hambleton, 2011), ${ }^{7}$ stimulating together with various relevant stakeholders, internal and external to the region, a transformational vision of the territory. The main assumption is that the development of place-based leadership involves substantive knowledge ("know what"), networks ("know who") and skills ("know how") to implement the process (European Commission, 2011). It is assumed that the university can be the facilitator of this process, ensuring the improvement of skills and connections within the system. 
The strategy of place-based leadership illustrates the importance of "social innovations" related to the influence of cultural and social factors in innovation and local development, specially the factors that can be mobilized as capital assets. The capital represents a complex process involving the relationship and value of a particular group of actors which can be activated to produce benefits (Field, 2003). It relates directly to the notion of embeddedness (Granovetter, 1985), which suggests that the actors do not work outside a social context, but in accordance to the socio-cultural categories they occupy within a network. Nevertheless, the connection of these processes with the more regular notion of innovation related to the capacity to generate economic value is one of the main unresolved issues, both in specialized literature and in policy-making.

\subsection{Towards an Integrated Approach}

The above discussions on the uses of the university illustrate the potential of several aspects that may be useful for decision-making. It is useful to highlight the importance of the relationship between dimensions in order to obtain more effective impacts on local contexts. The suggested framework of analysis assesses several apparently disparate streams, underlining the multiple uses of the university and identifying common responses and challenges in urban regeneration strategies. From a policy-making point of view, the four dimensions can be considered as "focused slices" (OECD, 2011). Given the different situation and opportunities, governments may consider focusing primarily on one or some specific aspects. Nevertheless, it is important to take into account the interrelations of dimensions. Figure 1 is an attempt to illustrate the connections for an integrated approach. The directions of the lines represent the main influence that one aspect may have on the other. They mean that for unfolding the potential benefits in one dimension, it is convenient to activate other dimensions.

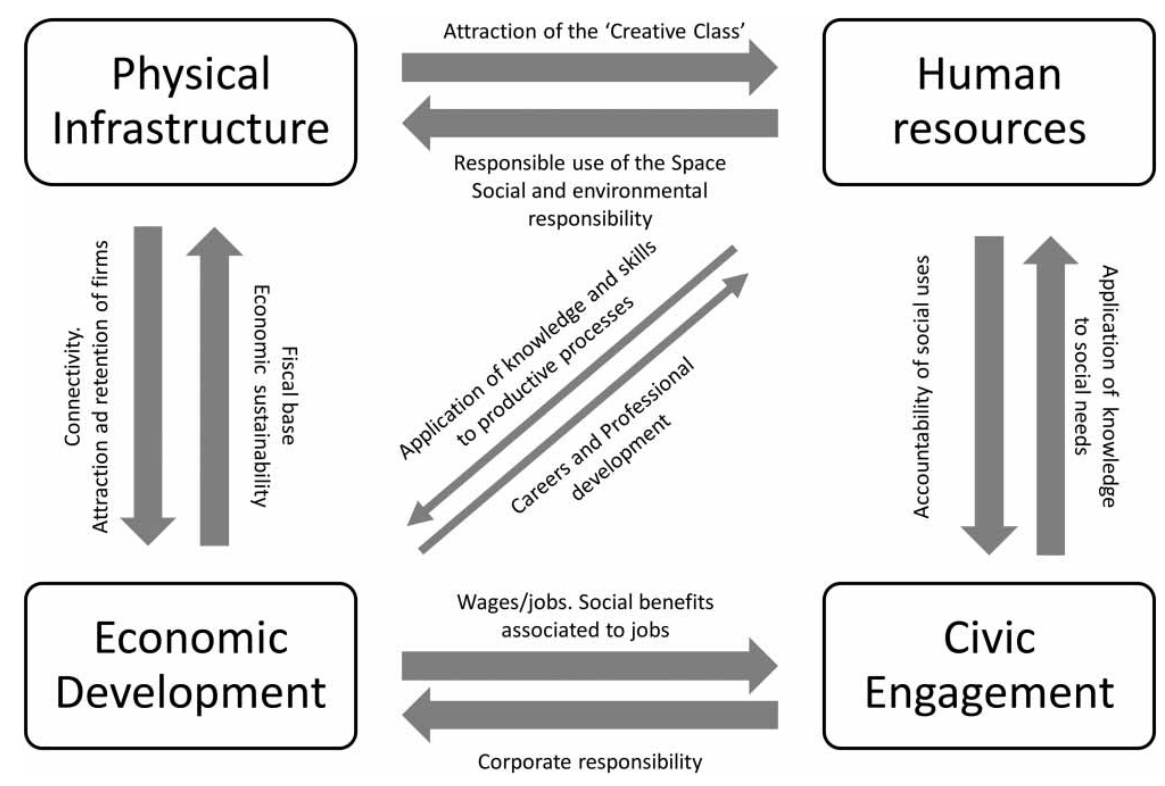

Figure 1. Universities and urban regeneration: interrelating the key dimensions. 
For instance, there is an interrelation between physical infrastructure and human resources. Some facilities contribute to the attraction of skilled human resources, while the presence of the educated population may facilitate a rational and sustainable use of the space. Physical infrastructures also show a clear connection to the economic base. On the one hand, some facilities are necessary for connecting businesses with external markets and are an essential component for attracting and retaining firms. On the other hand, the presence of firms becomes a necessary condition for building a fiscal base for supporting such infrastructures. In turn, the economic fabric is strongly related to the presence of human resources. The retention of firms is based on the local supply of skilled personnel whose knowledge is useful for productive process, while the presence of certain types of firms is one of the conditions for the careers trajectories of people with professional and technical qualifications. Finally, the civic and social dimension is also related to other components. The presence of qualified personnel provides better accountability of public issues, while the civic initiatives are usually a better way to both apply knowledge to social needs that are important for the community and to encourage corporate responsibilities of firms towards social issues.

\section{Discussion and Conclusions}

Universities are sources of economic and social progress for the territorial contexts in which they are located. This article has argued that increasingly HEIs are expected to play functions that go beyond the traditional missions of education and research, to stimulate the dynamics of regional and city development. However, studies addressing the uses of universities are highly diverse, reflecting universities' multiple roles and the variety of effects they produce. It has been show that research in this field and policies to link universities to urban development are fragmentary. Innovation studies usually focus on the national or the regional level, while studies on urban development do not usually consider HEIs to be significant actors in urban regeneration. Although there is currently a tendency to link uses of universities with the local level, this remains a somewhat disjointed area of study. We have claimed that the different roles of higher education and research should be understood in a holistic way when viewed from the standpoint of urban regeneration. To this end, four dimensions related to urban regeneration have been integrated into the discussion of knowledge transfer with university organizations and analysed in relation to city benefits. The indirect and planned effects have been shown, identifying tools and mechanisms of action likely to generate impacts in urban environments.

However, the article has privileged the desired impacts, rather than the common situation of institutional separation that is often found in many university environments in the developed world. Despite intensified policy attention and the growth in the number of studies in academia investigating the contribution of universities in innovation and economic development processes, recent work has also begun to question the high level of policy expectations, with little understanding of the actual processes of knowledge flows, and the extent to which territorial economic development can be actually achieved through the utilization of university knowledge.

A relevant question would be the following: is it possible to combine the university's institutional expectations with local needs? A number of studies suggest that the key issue is the institutionalization of practices that link these two worlds, each with very different value systems, capabilities and objectives (Molas-Gallart et al., 2002; Westnes et al., 2009). If we apply this discussion to strategies for urban regeneration, the difficulty 
of involving the universities without a process of institutional design complementing capacities with local bodies becomes apparent. This results in a series of significant policy and management implications on three levels.

First of all, there is a need to facilitate the interaction between actors who usually belong to different institutional spheres, what Etzkowitz and Ranga (2010) define as "consensus spaces" or other authors call as "territorial development coalitions" (Asheim \& Coenen, 2005). With this in mind, the link between local and university governing bodies requires partnerships to be created that lead to spaces that go beyond being merely points of contact between teachers and urban planning offices to carry out short-term consulting activities. This requires hybrid organizations and arrangements to channel demand and allocate resources. At the local level, the partnerships should be more diverse than the triple helix arrangements consisting in university, firms and governments. They should include the key actors in the value chain along areas or practice, such us providers of vocational education, knowledge-intensive knowledge providers, both in the professional and technology fields, as well as experienced researchers. This would make it possible to avoid the risks and unintended effects that may otherwise result from the diversification of university roles. Specifically, one risk to be avoided is that of unlinking the university from excellence goals, as this can lead to loss of legitimacy or the university's coming into competition with the private sector, or to its loss of human capital due to the loss of its connection with global advances in science.

Second, universities should adapt their policies to accept this kind of institutional development. Given that they are subject to inertial structures that usually take long time to adopt institutional renewal, it requires the introduction of incentive structures and specialized evaluation procedures in evaluation agencies, with management units that are able to oversee other functions. On the one hand, it is necessary to create professional profiles and specialized careers with structures different from those commonly existing for scientific and academic staff. On the other hand, the engagement of university staff with various spheres of urban regeneration requires specific assessment based on the workload while performing third mission activities.

Third, from the standpoint of local governments, it is necessary to have units enabling communication with the university to be maintained in a way that is based on similar cognitive frameworks and cultural practices. This requires the ability to capture and use knowledge from the university, which relies on the availability of professionals who can perform tasks equivalent to "technology watch", tailored to the specific processes of regeneration taking place in each urban environment. The qualification of human resources may require identification of specific technological capabilities in areas such as those associated with declining industrial sectors on which actions are to be focused, or the scientific university output in areas such as the humanities and social sciences in those environments with opportunities to use cultural resources as assets for regeneration. The professional training and awareness of people working in local government on issues like urban regeneration, technological performance, commercialization of university research and technology are key issues. It is then the task of the university to train such people and fill these gaps. In sum, a clear connection emerges between governance needs and provision of targeted training by universities in key areas of governance and development.

\section{Acknowledgements}

This paper is part of the grant CSO2010-14880 funded by the Spanish R\&D National Scheme. The paper has benefited enormously from the discussions of the COST Action 
TU0803 "Cities Regrowing Smaller (CIRES): Fostering Knowledge on Regeneration Strategies in Shrinking Cities across Europe". The authors also acknowledge the comments on earlier drafts received from Peter Franz and two anonymous referees.

\section{Notes}

1. For clarification purposes, in this article HEI is considered a synonym of universities and other higher education organizations and public research laboratories.

2. We follow Merton's (1987, p. 2) notion of strategic research site as “(...) research materials, sites, objects, or events that exhibit the phenomena to be explained or interpreted to such advantage and in such accessible form that they enable the fruitful investigation of previously stubborn problems and the discovery of new problems for further inquiry".

3. The concept of third mission is normally used to refer to the varied set of activities outside the two traditional core functions of universities: formal teaching and scientific research. They encompass a complex group of tasks of very different nature. Some authors argue that a "fourth mission" is emerging (Goddard, 2009), trying to differentiate the social purposes from the direct commercial activities. Nevertheless, given the difficulties for disentangling some social and economic benefits at local level, we prefer to use the term third mission or third stream.

4. The vision of a deeper role of the HEIs in regional development is also clearly stated in the preparation guidelines for the strategies for the 2014-2020 programming period, especially those under the RIS3 programme (European Commission, 2010).

5. Although it can be argued that all the above components may have economic and social implications, for analytical purposes it is worth dealing with them separately.

6. Shrinking cities are defined as "populated areas that on the one hand faced a population loss and on the other hand are undergoing economic transformation with symptoms of structural crisis" (Martinez-Fernandez et al., 2012). In addition, other related situations are population and productive dynamics that results in stagnation process.

7. The place-based civic leadership can be broadly defined as any activity that leadership serves a public purpose at a given location. In simple terms, can be distinguished from other types of leadership that are a-territorial (Hambleton, 2011).

\section{References}

Asheim, B. \& Coenen, L. (2005) Knowledge bases and regional innovation systems: Comparing Nordic clusters, Research Policy, 34, pp. 1173-1190.

Asheim, B. T., Coenen, L., Moodysson, J. \& Vang, J. (2007) Constructing knowledge-based regional advantage: Implications for regional innovation policy, International Journal of Entrepreneurship and Innovation Management, 7(2-5), pp. 140-155.

Bathelt, H., Malmberg, A. \& Maskell, P. (2004) Clusters and knowledge: Local buzz, global pipelines, and the process of knowledge creation, Progress in Human Geography, 28, pp. 31-56.

Benneworth, P. \& Charles, D. (2005) University spin-off policies and economic development in less successful regions: Learning from two decades of policy practice, European Planning Studies, 13(4), pp. 537-557.

Benneworth, P., Charles, D. \& Madanipour, A. (2010) Building localized interactions between universities and cities through university spatial development, European Planning Studies, 18(10), pp. 1611-1629.

Boyte, H. \& Hollander, E. (1999) Wingspread Declaration on Renewing the Civic Mission of the American Research University: The Wingspread Conference (Racine, WI: Campus Compact).

Carrillo, F. (Ed.) (2006) Knowledge Cities: Approaches, Perspectives and Experiences (Oxford: ButterworthHeinemann).

Casaleiro, P. (2011) Changing from a university city to a knowledge city: The case of Coimbra, International Journal of Knowledge Based Development, 2(2), pp. 25-38.

Clark, B. T. (1988) Creating Entrepreneurial Universities: Organizational Pathways of Transformation. Issues in Higher Education (New York: Pergamon).

Cook, P. (2005) Regionally asymmetric knowledge capabilities and open innovation exploring "Globalization 2": A new model of industry organization, Research Policy, 34, pp. 1128-1149. 
Couch, C., Fraser, Ch. \& Percy, S. (2003) Urban Regeneration in Europe (Oxford: Blackwell Science).

Couch, C., Sykes, O. \& Börstinghaus, W. (2011) Thirty years of urban regeneration in Britain, Germany and France: The importance of context and path dependency, Progress in Planning, 75(1), pp. 1-52.

Crane, D. (1972) Invisible Colleges: Diffusion of Knowledge in Scientific Communities (Chicago: University of Chicago Press).

Diamond, R. M. (1999) Aligning Faculty Rewards with Institutional Mission: Statement, Policies and Guidelines (Bolton, MA: Anker).

Drori, G., Meyer, J., Ramírez, F. \& Schofer, E. (2003) Science in the Modern World: Institutionalization and Globalization (Stanford, CA: Stanford University Press).

ESF-European Science Foundation. (2007) Higher Education Looking Forward: Relations Between Higher Education and Society (Brussels: ESF Forward Look Document).

Etzkowitz, H. \& Klofsten, M. (2005) The innovating region: Toward a theory of knowledge-based regional development, $R \& D$ Management, 35, pp. 243-255.

Etzkowitz, H. \& Ranga, M. (2010) A triple Helix system for knowledge-based regional development: From "spheres" to "spaces", in: The VIII Triple Helix International Conference, October 20-22, Madrid.

Etzkowitz, H., Webster, A., Gebhardt, C., Regina, B. \& Terra, C. (2000) The future of the university and the university of the future: Evolution of ivory tower to entrepreneurial paradigm, Research Policy, 29(2), pp. 313330.

EU Ministers for Urban Development. (2010) Toledo Informal Ministerial Meeting on Urban Development. Toledo Declaration. Available at http://ec.europa.eu/regional_policy/newsroom/pdf/201006_toledo_declaration_en. pdf (accessed 12 February 2012).

European Commission. (2010) Communication from the Commission-Europe 2020 A Strategy for Smart, Sustainable and Inclusive Growth (Brussels, 3.3.2010), COM(2010) 2020. Available at http://ec.europa.eu/ eu2020/pdf/COMPLET\%20EN\%20BARROSO\%20\%20\%20007\%20-\%20Europe\%202020\%20-\%20EN\% 20version.pdf (accessed 11 January 2012).

European Commission. (2011) Connecting Universities to Regional Growth: A Practical Guide. DG Regio, Smart Specialization Platform.

Faggian, A. \& McCann, P. (2009) Human capital, graduate migration and innovation in British regions, Cambridge Journal of Economics, 33(2), pp. 317-333.

Fernández-Esquinas, M., Merchán-Hernández, C., Ramos-Vielba, I. \& Martínez-Fernández, C. (2010) Key knowledge providers as sources of business innovation, Industry and Higher Education, 24(3), pp. 189-201.

Field, J. (2003) Social Capital (London: Routledge).

Flew, T. (2012) The Creative Industries, Culture and Policy (London: Sage).

Florida, R. (2003) Rise of the Creative Class: And How It's Transforming Work, Leisure, Community and Everyday Life (New York: Basic Books).

Franz, P. (2008) From university town to knowledge city: Strategies and regulatory hurdles Germany, in: T. Yigitcanlar, K. Velibeyoglu \& S. Baum (Eds) Knowledge-Based Urban Development: Planning and Applications in the Information Era, pp. 101-115 (Hershey, PA: IGI Global).

Franz, P. (2010) Knowledge spill-overs for knowledge based development: Progression in theory and obstacles for empirical research, International Journal of Knowledge Based Development, 1(1-2), pp. 25-38.

Franz, P. (2011) Editorial: Attempts to bring knowledge, universities and special development together, International Journal of Knowledge-Based Development, 2(2), pp. 129-131.

Fritsch, M. \& Monz, M. (2010) The impact of network structure on knowledge transfer: An application of social network analysis in the context of regional innovation networks, Annual Regional Science, 44, pp. 21-38.

Goddard, J. (2009) Reinventing the Civic University, Provocation 12: September 2009, NESTA.

Granovetter, M. (1985) Economic action and social structure: The problem of embeddedness, American Journal of Sociology, 91(3), pp. 481-510.

Guerreiro, J. \& Pinto, H. (2012) The engaged university and institutional changes in Portuguese innovation systems, International Journal of Transitions and Innovation Systems, 2(1), pp. 72-90.

Gunasekara, C. S. (2006) The generative and developmental roles of universities in regional innovation systems, Science and Public Policy, 33, pp. 137-150.

Guston, D. H. (1999) Stabilizing the boundary between US politics and science: The role of the office of technology transfer as a boundary organization, Social Studies of Science, 29(1), pp. 87-111.

Hambleton, R. (2011) Place-based leadership in a global era, Commonwealth Journal of Local Governance, 8/9(May-November), pp. 8-32. 
Harkavy, I. (2000) Service-learning, academically based community service, and the historic mission of the American urban research university, in: I. Harkavy \& B. M. Donovan (Eds) Connecting Past and Present: Concepts and Models for Service-Learning in History, pp. 27-41 (Washington, DC: American Association for Higher Education).

Kearns, A. \& Paddison, R. (2000) New challenges for urban governance, Urban Studies, 37(5-6), pp. 845-850.

Knieling, J. \& Othengrafen, F. (2009) En route to a theoretical model for comparative research, in: J. Knieling \& F. Othengrafen (Eds) Planning Cultures in Europe-Decoding Cultural Phenomena in Urban and Regional Planning, pp. 39-62 (Farnham: Ashgate).

Landry, C. (2000) The Creative City. A Toolkit for Urban Innovators (London: Comedia-Earthscan).

Lindelöf, P. \& Löfsten, H. (2003) Science park location and new technology-based firms in Swedenimplications for strategy and performance, Small Business Economics, 20, pp. 245-258.

Mansfield, E. (1991) Academic research and industrial innovation, Research Policy, 20, pp. 1-12.

Martinez-Fernandez, C., Audirac, I., Fol, S. \& Cunningham-Sabot, E. (2012) Shrinking cities: Urban challenges of globalization, International Journal of Urban and Regional Research, 36, pp. 213-225.

McCarthy, J. \& Allan Pollock, S. H. (1997) Urban regeneration in Glasgow and Dundee: A comparative evaluation, Land Use Policy, 14(2), pp. 137-149.

Merton, R. (1987) Three fragments from a sociologist's notebook: Establishing the phenomenon, specified ignorance, and strategic research materials, Annual Review of Sociology, 13, pp. 1-28.

Molas-Gallart, J., Salter, A., Patel, P., Scott, A. \& Duran, X. (2002) Measuring Third Stream Activities, Final Report to the Russell Group of Universities (Brighton: SPRU, University of Sussex).

Moulaert, F. \& Sekia, F. (2003) Territorial innovation models: A critical survey, Regional Studies, 37(3), pp. 289-302.

Mustard, S. \& Murie, A. (Eds) (2010) Making Competitive Cities (London: Wiley-Blackwell).

O'Mara, M. (2007) Landscapes of knowledge: History and the evolving geography of high technology, Places, 19(1), pp. 48-53.

O'Mara, M. (2012) Beyond the town and gown: University economic engagement and the legacy of the urban crisis, Journal of Technology Transfer, 37(2), pp. 234-250.

OECD. (2007) Higher Education and Regions: Globally Competitive, Locally Engaged (Paris: OECD).

OECD. (2011) Public Research Institutions: Mapping Sector Trends (Paris: OECD).

Paddison, R. \& Miles, S. (Eds) (2007) Culture-led Urban Regeneration (London: Routledge).

Perry, D. (2005) The University as Urban Developer: Case Studies and Analysis (Cambridge, MA: Armonk).

Pinto, H., Fernández-Esquinas, M. \& Uyarra, E. (2011) Universities and KIBS as providers of firm innovation, in: Regional Studies Association Research Network Seminar Series, Policy Implication of KIBS and innovation in Regions, October 14-15, Faro, Portugal.

Ramos-Vielba, I. \& Fernández-Esquinas, M. (2009) Beneath the tip of the Iceberg: The multiple forms of university-industry collaborative linkages, in: The Atlanta Conference on Science and Innovation Policy Proceedings, 2-3 October, Atlanta, GA, USA, Georgia Institute of Technology.

Rantisi, N. (2002) The local innovation system as a source of "variety": Openness and adaptability in New York city's garment district, Regional Studies, 36(6), pp. 587-602.

Roberts, P. \& Sykes, H. (2000) Urban Regeneration. A Handbook (London: Sage).

Rodríguez Gómez, R. (1999) La universidad latinoamericana en la encrucijada del siglo XXI, Revista Iberoamericana de Educación, N. 21. Available at http://www.rieoei.org/rie21a04.htm (accessed 12 September 2011).

Rowe, G. \& Frewer, L. J. (2000) Public participation methods: A framework for evaluation, Science, Technology \& Human Values, 25(1), pp. 3-29.

Saxenian, A. L. (1996) Regional Advantage: Culture and Competition in Silicon Valley and Route 128 (Cambridge, MA: Harvard University Press).

Simmie, J. \& Strambach, S. (2006) The contribution of KIBS to innovation in cities: An evolutionary and institutional perspective, Journal of Knowledge Management, 10(5), pp. 26-40.

Uyarra, E. (2010) Conceptualizing the regional roles of universities, implications and contradictions, European Planning Studies, 18(8), pp. 1227-1246.

Watson, D. (2007) Managing Civic and Community Engagement (Milton Keynes: Oxford University Press).

Wergin, J. (2006) Elements of effective community engagement, in: S. L. Percy, N. L. Zimpher \& M. J. Brukardt (Eds) Creating a New Kind of University: Institutionalizing Community-University Engagement, pp. 23-44 (Boston, MA: Anker).

Westnes, P., Hatakenaka, S., Gjelsvik, M. \& Lester, R. K. (2009) The role of universities in strengthening local capabilities for innovation-a comparative case study, Higher Education Policy, 22, pp. 483-503. 